\title{
Correction to: The association between anxiety and disease activity and quality of life in rheumatoid arthritis: a systematic review and meta-analysis
}

Annabelle R. Machin ${ }^{1}$ (1) - Opeyemi Babatunde ${ }^{1} \cdot$ Randula Haththotuwa $^{1} \cdot \operatorname{lan}$ Scott $^{1,2} \cdot$ Milica Blagojevic-Bucknall $^{1}$. Nadia Corp ${ }^{1}$ - Carolyn A. Chew-Graham ${ }^{1,3,4}$. Samantha L. Hider ${ }^{1,2,4}$

Published online: 4 February 2020

(C) International League of Associations for Rheumatology (ILAR) 2020

\section{Correction to: Clinical Rheumatology} https://doi.org/10.1007/s10067-019-04900-y

The Figure 2 of the published original version of the above article is incorrect. The correct Figure 2 shown in this article.

The online version of the original article can be found at https://doi.org/ 10.1007/s10067-019-04900-y

Annabelle R. Machin

a.r.machin@keele.ac.uk

1 Primary Care Centre Versus Arthritis, School for Primary,

Community and Social Care, Keele University, Staffordshire ST5

$5 \mathrm{BG}, \mathrm{UK}$

2 Haywood Academic Rheumatology Centre, Midlands Partnership Foundation Trust, Staffordshire, UK

3 West Midlands CLAHRC, West Midlands, UK

4 Midlands Partnership Foundation Trust, Staffordshire, UK 
First Author/ Year

$n=$ number of participants

Al-Fadl [28] 2014

$\mathrm{n}=26$

Karahan [37] 2016.

$\mathrm{n}=148$

Matcham [39] 2016.

$n=56$

Ruhalia [42] 2018.

$\mathrm{n}=189$

Zulgerel [44] 2014

$\mathrm{n}=51$

Overall (I-squared $=0 \%, p=0.427$ )

NOTE: Weights are from random effects analysis

\section{a Anxiety and DAS28}

$r(95 \% \mathrm{Cl})$

$0.47(0.10,0.73)$

$0.16(-0.00,0.31)$

$0.29(0.03,0.51)$

$0.23(0.09,0.36)$

$0.13(-0.16,0.39)$

$0.23(0.14,0.31)$

First Author/ Year

$\mathrm{n}=$ number of participants

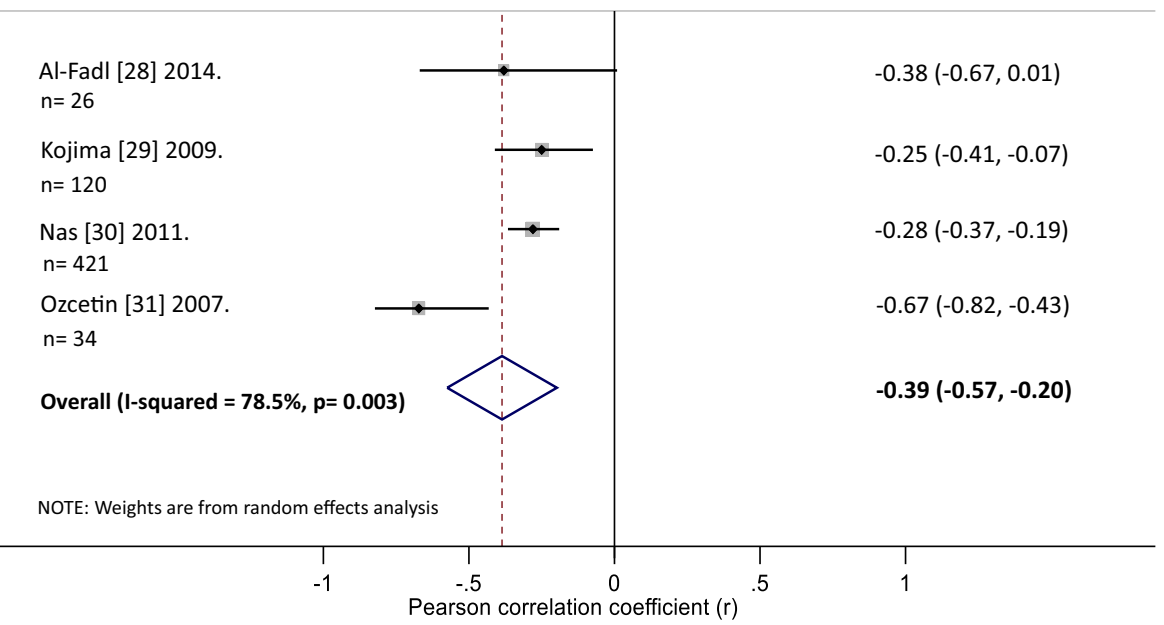

First Author/ Year

$n=$ number of participants

Al-Fadl [28] 2014.

$n=26$

Kojima [29] 2009.

$\mathrm{n}=120$

Nas [30] 2011.

$n=421$

Ozcetin [31] 2007.

$\mathrm{n}=34$

Overall $(I-$ squared $=10.3 \%, p=0.341)$

c Anxiety and Mental QoL

b Anxiety and Physical QoL 
4 Fig. 2 Forest plots of the meta-analysis of correlation coefficients between (a) Anxiety and DAS28, (b) Anxiety and Physical QoL and (c) Anxiety and Mental QoL
Publisher's note Springer Nature remains neutral with regard to jurisdictional claims in published maps and institutional affiliations. 